\title{
Impaired neuroanatomic development in infants with congenital heart disease
}

\author{
Kazuhiro Watanabe, MD, ${ }^{\text {a }}$ Mie Matsui, MD, ${ }^{\mathrm{b}}$ Junko Matsuzawa, MD, ${ }^{\mathrm{a}}$ Chiaki Tanaka, MD, ${ }^{\mathrm{a}}$ Kyo Noguchi, MD, ${ }^{\mathrm{c}}$ \\ Naoki Yoshimura, MD, ${ }^{\mathrm{d}}$ Kazuhisa Hongo, MD, ${ }^{\mathrm{a}}$ Mayumi Ishiguro, PhD, ${ }^{\mathrm{b}}$ Sayaka Wanatabe, MD, ${ }^{\mathrm{a}}$ Keiich Hirono, MD, ${ }^{\mathrm{a}}$ \\ Keiichiro Uese, MD, ${ }^{\text {a }}$ Fukiko Ichida, MD, ${ }^{a}$ Hideki Origasa, PhD,${ }^{\mathrm{e}}$ Jun Nakazawa, MD, ${ }^{\mathrm{f}}$ Yoshihiro Oshima, MD, ${ }^{\mathrm{g}}$ \\ Toshio Miyawaki, MD, ${ }^{\mathrm{a}}$ Tachiyo Matsuzaki, PhD, ${ }^{\mathrm{h}}$ Toshikatsu Yagihara, MD, ${ }^{\mathrm{h}}$ Warren Bilker, PhD, ${ }^{\mathrm{i}}$ and Ruben C. Gur, MD
}

Objectives: We performed a regional volumetric study of the brain using 3-dimensional magnetic resonance imaging in infants with congenital heart disease to search for variables in anatomic development of the brain that may be associated with functional impairment.

\begin{abstract}
Methods: Forty infants with congenital heart disease -17 infants with single ventricle physiology, 5 with transposition of great arteries, and 18 with ventricular septal defect-were studied prospectively by 3 -dimensional magnetic resonance imaging of the brain several months after heart surgery.

Results: The global volume of gray matter was significantly reduced in the patients with congenital heart disease compared with normal controls $(P<.001)$, whereas no significant difference in the volume of white matter was observed. Further, the decrease in gray matter volume was more apparent in the frontal lobe than in the temporal lobe, especially in infants with single ventricle physiology or transposition of the great arteries. Multivariate analysis revealed that preoperative hypoxia is strongly associated with decreased frontal gray matter volume $(P<.01)$, as well as a diagnosis of hypoplastic left heart syndrome $(P<.05)$. Of note, frontal gray matter volume, which includes the motor area, correlated weakly with psychomotor developmental index scores $(P<.01)$.

Conclusions: Brain developmental impairment occurs in many infants with congenital heart disease, especially in those who have preoperative hypoxia and critical congenital heart disease. This quantitative volumetric study encourages larger scale and longitudinal follow-up to elucidate the significance of impaired neuroanatomic development on functional outcome.
\end{abstract}

Recent advances in diagnostic and surgical techniques have enabled early correction of most complex congenital heart diseases (CHD) in infancy and have dramatically reduced mortality. ${ }^{1,2}$ However, a considerable rate of neurologic sequelae is observed after heart surgery in infants. ${ }^{3-6}$ The etiology is multifactorial with the integrity of the developing nervous system being influenced by a complex interaction of perioperative factors in infants with CHD. ${ }^{7,8}$ Newborns with critical CHD have widespread brain abnormalities before undergoing cardiac surgery, possibly caused by impaired cerebral oxygen delivery and impaired brain development in utero. ${ }^{9}$ Newborns with transposition of the

From the Department of Pediatrics, ${ }^{a}$ Psychology, ${ }^{\mathrm{b}}$ Radiology, ${ }^{\mathrm{c}}$ and Cardiothoracic Surgery, ${ }^{\mathrm{d}}$ Division of Biostatistics, ${ }^{\mathrm{e}}$ University of Toyama, Toyama; Department of Psychology, ${ }^{\mathrm{f}}$ Chiba University, Chiba; Department of Cardiothoracic Surgery, ${ }^{\mathrm{g}}$ Hyogo Children's Hospital, Kobe; Department of Cardiothoracic Surgery, ${ }^{\text {h }}$ National Cardiovascular Center, Osaka, Japan; and the Department of Biostatistics and Epidemiology ${ }^{\mathrm{i}}$ and Psychiatry, ${ }^{\mathrm{j}}$ University of Pennsylvania, Philadelphia, Pa.

This study was supported by grants from Core Research for Evolutional Science and Technology (Japan Science and Technology Agency) and Japanese Study of Cognitive Function after Open Heart Surgery in Pediatric Patients (Ministry of Health, Labour and Welfare).

Received for publication March 23, 2008; revisions received May 29, 2008; accepted for publication June 24, 2008.

Address for reprints: Fukiko Ichida, MD, Department of Pediatrics, University of Toyama, 2630 Sugitani, Toyama, Toyama, 930-0194 Japan (E-mail: fukiko@ med.u-toyama.ac.jp).

J Thorac Cardiovasc Surg 2009;137:146-53

$0022-5223 / \$ 36.00$

Copyright (c) 2009 by The American Association for Thoracic Surgery doi:10.1016/j.jtcvs.2008.06.036 great arteries (TGA) or single ventricle (SV) physiology have altered brain metabolism and microstructure shortly after birth, even in the absence of visible injury on magnetic resonance imaging (MRI). ${ }^{9}$ However, these subtle brain abnormalities are difficult to elucidate in infancy, and the final neurologic outcome can only be determined by developmental testing late after the operation. ${ }^{10-12}$

Most infants with critical CHD, especially hypoplastic left heat syndrome (HLHS), have a reduced head circumference. ${ }^{13}$ Nevertheless, there are no data regarding exact brain volume and its relation to neurodevelopment in infants with critical CHD. We hypothesized that infants with critical CHD have impaired anatomic development of the brain, and this is associated with functional impairment. We performed a regional volumetric study of the brain using 3dimensional magnetic resonance imaging (3D-MRI) in infants with heterogeneous CHD including SV, TGA, and ventricular septal defect (VSD) and performed neurodevelopmental assessment using the Bayley Scales of Infant Development II.

\section{METHODS}

\section{Patients}

A prospective observational study was performed in 40 infants with CHD from May 2005 to April 2007. The patients were further classified into those who had critical CHD including TGA and SV (critical CHD group) and those who had a diagnosis of VSD (VSD group). Infants were excluded if their gestational age was less than 36 weeks or if there was 

Abbreviations and Acronyms
$\mathrm{CHD}=$ congenital heart disease
$\mathrm{CSF}=$ cerebrospinal fluid
3D-MRI $=3$-dimensional magnetic resonance imaging
$\mathrm{GM}=$ gray matter
HLHS = hypoplastic left heart syndrome
MDI = mental developmental index
MRI = magnetic resonance imaging
PDI = psychomotor developmental index
SV $=$ single ventricle
TGA $=$ transposition of the great arteries
VSD $=$ ventricular septal defect
$\mathrm{WM}=$ white matter

a genetic malformation syndrome. A volumetric study of the brain using 3D-MRI was performed at least 2 months $(8.6 \pm 5.7$ months) after the latest heart surgery in each patient. Neurodevelopmental assessment was performed by the Bayley Scales of Infant Development II in all patients by a pediatric psychologist (M.I.). The interval between the 3D-MRI study and the neurodevelopmental assessment was less than 2 weeks in all patients. Preoperative clinical data were prospectively collected from the medical records and reviewed by pediatric cardiologists who were blinded to the 3D-MRI findings.

Nineteen healthy control infants (aged 1 month to 24 months) were recruited from University Hospital staff and siblings of ambulatory child patients for volumetric study of the brain. They were born at term without any complicated perinatal courses. Their heights and weights were all in the normal range. All controls had normal neurologic development and had no abnormal findings on routine MRI.

The Research Ethics Committee of the University Hospital of Toyama approved the study. Written informed consent was obtained from parents after the purpose and all procedures of the study were fully explained. All patients and controls were sedated with monosodium trichorethyl phosphate syrup $(0.5-1.0 \mathrm{~mL} / \mathrm{kg})$ before MRI.

\section{MRI Scan Acquisition}

MRI scans were performed as previously described with a $1.5-\mathrm{T}$ Magnetom Vision scanner (Siemens, Erlangen, Germany). ${ }^{14}$ In brief, axial images were obtained with a fast low-angle shot gradient refocused 3dimensional sequence with the following parameters: flip angle $=35^{\circ}$, repetition time $=35 \mathrm{~ms}$, echo time $=6 \mathrm{~ms}$, nex $=1$. The image obtained was T1-weighted with a field of view of $256 \mathrm{~mm}$ and a matrix size of 256 $\times 256$, and the entire scan was obtained in 15 minutes. The slice thickness was $1.0 \mathrm{~mm}$, and between 140 and 170 contiguous slices were obtained in each case.

\section{Image Processing}

Each acquisition was transferred to an online UNIX workstation (SPARC20; Sun Microsystems, Santa Clara, Calif). All image processing was performed with a semi-automated software package. ${ }^{15}$ Manual delineation of cerebral hemispheres and cerebrospinal fluid (CSF) was based on standard guidelines ${ }^{16}$ and frontal and temporal lobar volumes were calculated by previously described procedures. ${ }^{17}$

\section{Cerebral Hemispheres and CSF}

Collection of data in the axial plane required neuroanatomic knowledge to separate the supratentorial from infratentorial compartments. All supratentorial slices were analyzed and the infratentorial CSF and tissue were excluded by placing a boundary around the posterior fossa on each slice.

\section{Frontal and Temporal Lobes}

As described previously, ${ }^{14}$ we have added a new method of delineation to include more frontal lobar regions, such as the motor area. We measured the global volume of gray matter (GM), white matter (WM), CSF, and regional brain volume of the frontal lobe and temporal lobe in the patients and normal controls.

\section{Reliability of Regional Volumetric Measurements}

Inter-reader reliability was examined in a sample of 10 normal controls analyzed by two raters (K.W. and J.M.). The intraclass correlation for total cerebral volumes ranged from 0.93 to 1.02 and those of frontal and temporal lobar volumes from 0.95 to 0.99 . The intra-reader reliability was also examined in the same 10 scans analyzed by one of these readers (K.W.), and the correlation for total cerebral, frontal, and temporal lobar volumes ranged from 0.93 to 0.98 . The reader (K.W.) then completed the analysis on the remaining scans.

\section{Statistical Analyses}

In normal controls, the relationship between the whole brain volume compartment of GM, WM, CSF, and age was modeled by linear regression with fractional polynomials of age as the covariates. ${ }^{18}$ This approach finds the combination of fractional powers of age that best describe each of the relationships. Models with up to three fractional powers were explored. For all three models (GM, WM, and CSF), one fractional power of age was sufficient. In addition, the curve-fitting approach to examine age effects on the frontal and temporal subregions, including examination of tissue types, was done simultaneously by linear regression with fractional polynomials. In infants with CHD, the difference from a normal population over age was evaluated by the Wilcoxon signed rank test. Correlation between regional brain volume and neurodevelopmental score by Bayley II scale was assessed by $t$ test concerning the slope. Independent risk factors for the reduced regional brain volume were analyzed by multiple regression analysis after the standardization by age. Statistical computations were performed with STATA (STATA Corp, College Station, Tex) and SAS software (SAS Institute Inc, Cary, NC).

\section{RESULTS}

\section{Patient Clinical Characteristics}

Clinical characteristics of the patients are described in Table 1 . Of the infants with critical CHD, 17 had SV physiology including 4 with HLHS and 5 with TGA, whereas the VSD group included 15 infants with simple VSD and 3 with associated VSD and coarctation of the aorta. Preoperative oxygen saturation was significantly lower in the group with critical CHD. No significant differences were found in patient-related variables including age, body weight, height, and head circumference. Periventricular leukomalacia was diagnosed by ultrasonography in 2 patients in the critical CHD group during the neonatal period. Age at operation was significantly younger in the critical CHD group. Other perioperative variables, including duration of intubation were not significantly different between the two groups. Perioperative seizure was observed in only 1 patient in the critical CHD group. All of the VSD patients underwent total correction, whereas 17 of the patients with critical CHD 
TABLE 1. Patient characteristics and perioperative variables

\begin{tabular}{|c|c|c|c|}
\hline Variables & VSD group $(n=18)$ & Critical CHD group $(n=22)$ & $P$ value \\
\hline \multicolumn{4}{|l|}{ Patient-related variables } \\
\hline Age at examination $(\mathrm{mo})$ & $13.2 \pm 3.2$ & $15.5 \pm 6.1$ & NS \\
\hline Sex (male/female) & $11 / 7$ & $12 / 10$ & NS \\
\hline Body weight (Z) & $-0.21 \pm 1.13$ & $-0.99 \pm 1.50$ & NS \\
\hline Body height (Z) & $-0.25 \pm 1.32$ & $-1.20 \pm 1.42$ & NS \\
\hline Head circumference $(\mathrm{Z})$ & $-0.05 \pm 0.60$ & $-0.64 \pm 0.61$ & NS \\
\hline Gestational age (wk) & $39.4 \pm 1.5$ & $38.8 \pm 1.7$ & NS \\
\hline Birth weight (g) & $3059 \pm 447$ & $2996 \pm 360$ & NS \\
\hline Birth head & $0.07 \pm 0.85$ & $-0.21 \pm 0.55$ & NS \\
\hline \multicolumn{4}{|l|}{ circumference $(\mathrm{Z})$} \\
\hline \multicolumn{4}{|l|}{ Apgar score } \\
\hline At $1 \mathrm{~min}$ & $8.5 \pm 0.5$ & $7.6 \pm 1.8$ & \\
\hline At $5 \mathrm{~min}$ & $9.1 \pm 0.6$ & $8.5 \pm 1.3$ & \\
\hline PVL at neonatal period & 0 & 2 & \\
\hline \multicolumn{4}{|l|}{ Periorerative variables } \\
\hline $\begin{array}{l}\text { Age at latest } \\
\text { operation (d) }\end{array}$ & $201.8 \pm 158.7$ & $82.7 \pm 132.6$ & $<.05$ \\
\hline \multicolumn{4}{|l|}{ Oxygen saturation } \\
\hline Before surgery $(\%)$ & $97.6 \pm 3.6$ & $77.6 \pm 5.2$ & $<.001$ \\
\hline ACC duration (min) & $94.3 \pm 56.3$ & $91.4 \pm 45.4$ & NS \\
\hline ECC duration (min) & $154.0 \pm 84.3$ & $209.3 \pm 83.2$ & NS \\
\hline Duration of intubation (d) & $2.0 \pm 4.6$ & $5.1 \pm 5.4$ & NS \\
\hline Perioperative seizures & 0 & 1 & NS \\
\hline \multicolumn{4}{|l|}{ Diagnosis } \\
\hline TGA & & 5 & \\
\hline SV (HLHS) & & $17(4)$ & \\
\hline VSD (CoA) & $18(3)$ & & \\
\hline \multicolumn{4}{|l|}{ Latest surgical procedures } \\
\hline Palliative operation & & 17 & \\
\hline Stage 1 (Norwood, SP) & & $10(4,6)$ & \\
\hline Stage 2 (Glenn, Glenn+DKS) & & $7(5,2)$ & \\
\hline Total correction & 18 & 5 & \\
\hline
\end{tabular}

$V S D$, Ventricular septal defect; $C H D$, congenital heart disease; $Z$, Z-scores (body weight, height, and head circumference were expressed as Z-scores); $P V L$, periventricular leukomalacia; $A C C$, aortic crossclamp; $E C C$, extracorporeal circulation; $T G A$, transposition of great arteries; $S V$, single ventricle; $H L H S$, hypoplastic left heart syndrome; $V S D$, ventricular septal defect; $C O A$, coarctation of the aorta; $S P$, systemic-pulmonary shunt; $D K S$, Damus-Kaye-Stansel operation; NS, not significant.

underwent palliative operation and 5 underwent total correction (Table 1). Neuroexaminations, performed by a neuropediatrician (K.H.), revealed no significant abnormalities in any of the patients except for 1 floppy infant in the critical CHD group. Clinical review of the anatomic MRI scans by a neuroradiologist (K.N.) resulted in normal findings in all patients, except for 2 patients with slight subdural hematoma.

\section{Volumetry of the Brain by 3D-MRI}

Figure 1 shows representative MRIs of controls and patients with HLHS at different ages. Decreases in GM volume, especially frontal GM, are apparent in patients with HLHS compared with age-matched normal controls.

The distribution by age of the global volumes of GM and $\mathrm{WM}$, as well as the best fitting models for normal controls, are shown in Figure 2. As described previously, ${ }^{14}$ the volumes of both GM and WM increase rapidly during the first
2 years after birth. Further, the rate of increase in GM is greater than that in WM and reaches a maximum around 16 to 24 months of age. While the WM increases more steadily, it continues to increase after 24 months of age.

The distribution by age of the frontal and temporal volumes of GM and WM, as well as the best fitting models for normal controls, are shown in Figure 3.

Volumetric analysis revealed that the global volume of GM was significantly reduced in the patients with CHD compared with normal controls $(P<.001)$ (Figure 2, $A$ ). No significant differences in the global volume of WM were observed between the patients with CHD and normal controls (Figure 2, $B$ ). The decrease in global volume of GM was more apparent and significant $(P<.001)$ in the frontal lobe than that in temporal lobe in the patients with CHD (Figure 3, $A, B$ ). Further, a reduction in the volume of frontal lobe WM was also noted $(P<.01)$ (Figure 3,C). 




Healthy Control, $4 \mathrm{~m}$

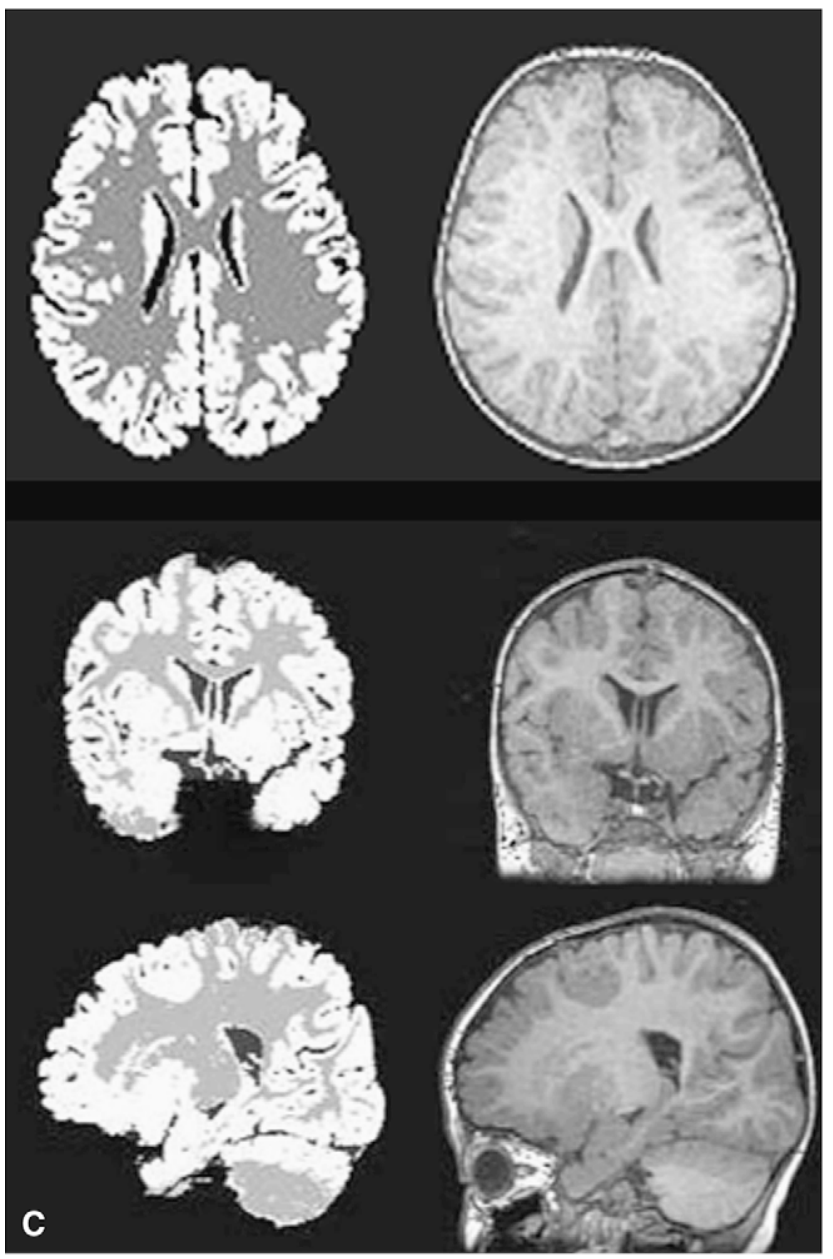

Healthy Control, 1y6m

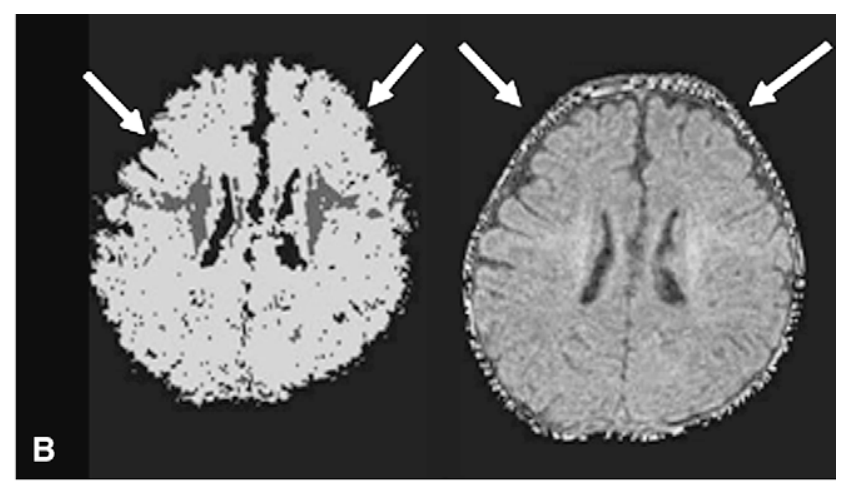

HLHS, $4 m$

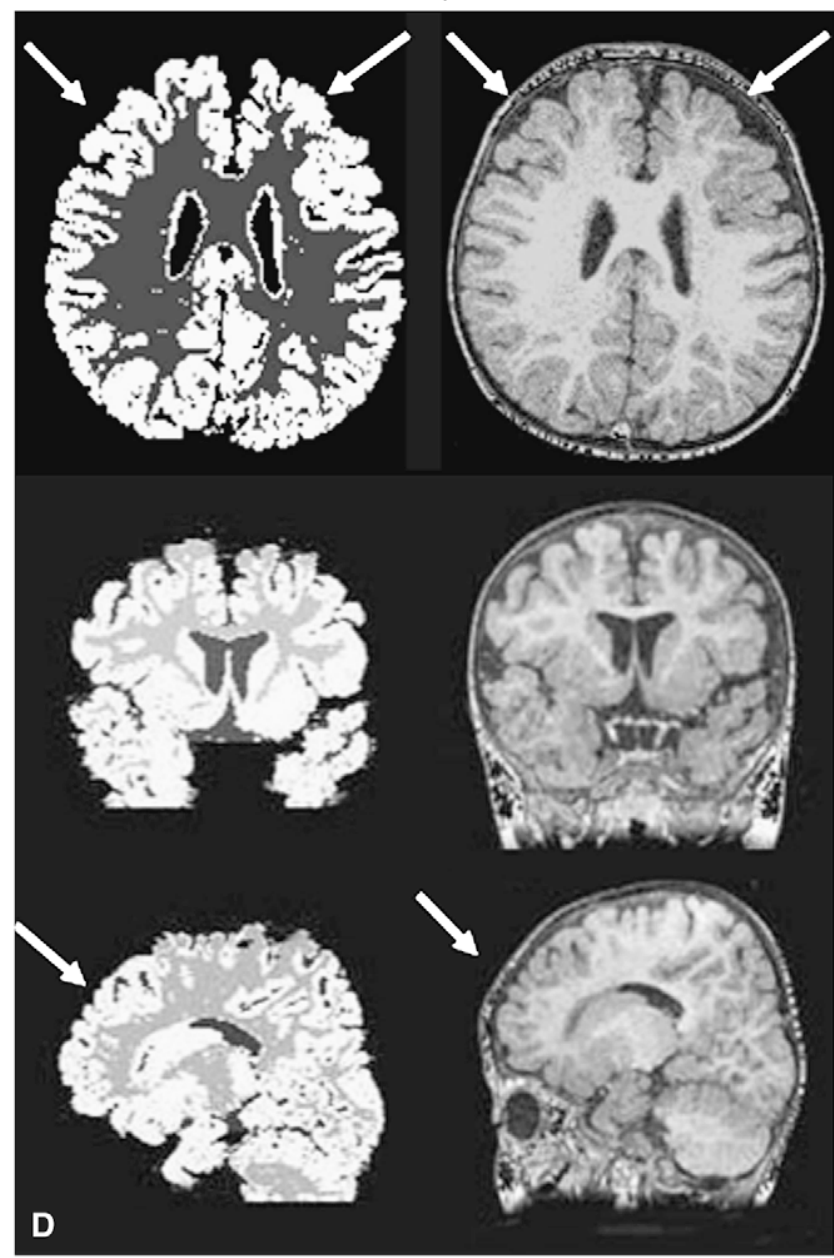

HLHS, 1y6m

FIGURE 1. Examples of tissue classification (left) and original T1-weighted images (right) from 4-month-old (A) and $1 \frac{1}{2}$-year- old (C) normal controls (A, axial image, C, axial, coronal, and sagittal images), and representative slices from patients with hypoplastic left heart syndrome (HLHS) at the same ages (B, axial image, D, axial, coronal, and sagittal images). Decrease of the gray matter volume, especially frontal lobe (white arrows), is appreciated in the HLHS patients compared with the age-matched controls. In the tissue classification images, the gray matter appears white, the white matter is gray and the cerebrospinal fluid is black.

Decreased GM Volume and Multivariate Risk Factor Analysis

Among the variables shown in Table 2, preoperative oxygen saturation was strongly associated with decreased frontal GM volume in this cohort $(P<.01)$. HLHS and body weight were also associated with decreased frontal GM volume $(P<.05)$. Other variables, such as Apgar score, birth head circumference, age at latest operation, body 

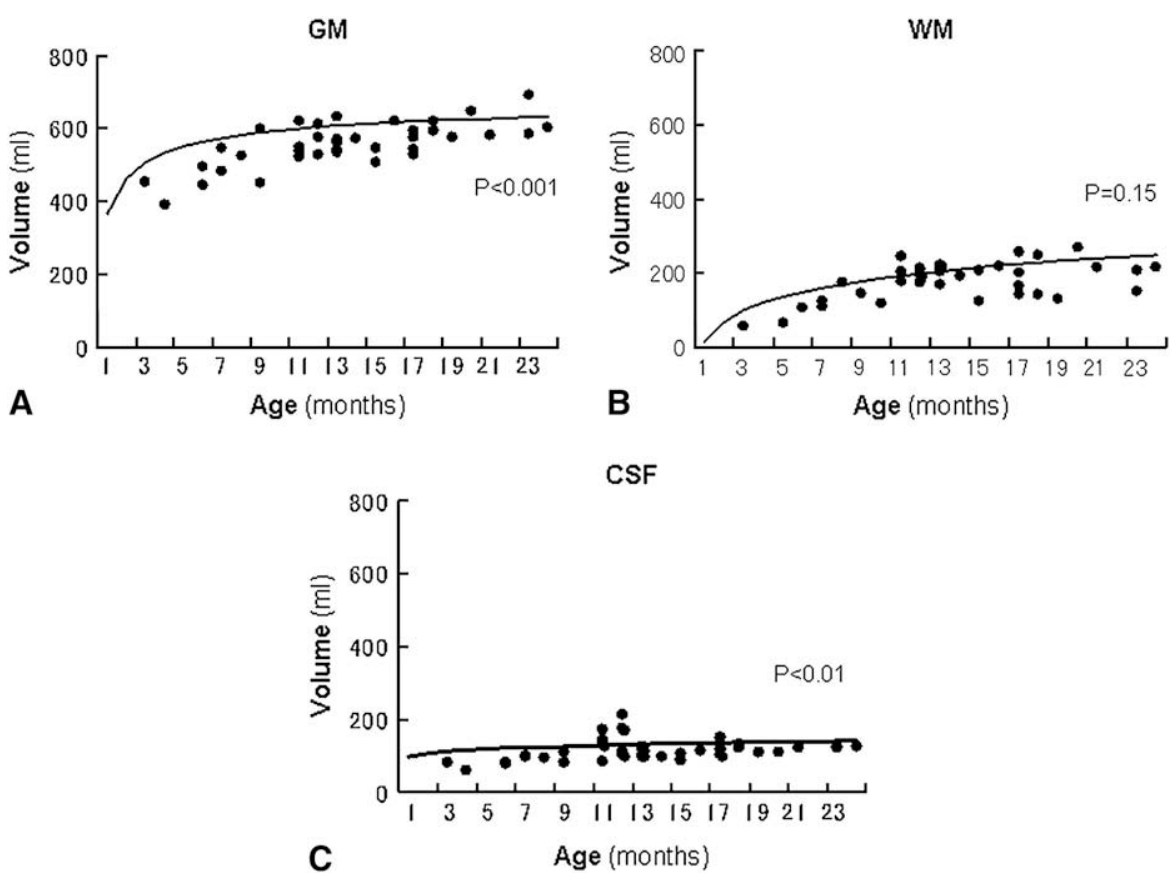

FIGURE 2. The distribution by age of the global volumes of gray matter $(G M, \mathrm{~A})$, white matter $(W M, \mathrm{~B})$, and cerebrospinal fluid $(C S F$, C). The line shows best fitting models for normal controls. For global volume of GM, WM, and CSF, the best fitting models for normal controls were as follows: GM $=718.84+$ $89.12 \times Z$, where $Z=\operatorname{In}($ age $/ 100)+0.76 ; \mathrm{WM}=320.49+88.59 \times \mathrm{Z}$, where $Z=\operatorname{In}($ age $/ 100)+0.76 ; \mathrm{CSF}=122.99+8.32 \times Z$, where $Z=\operatorname{In}($ age $/ 100)+$ 0.76. Closed circles represent each of the patients with congenital heart diseae.

height, head circumference at study, duration of aortic crossclamp, duration of extracorporeal circulation, duration of intubation, and duration of intensive care unit stay did not correlate with decreased GM volume.

\section{Neurodevelopmental Assessment and Regional Brain Volumes by 3D-MRI}

Delayed mental development (MDI score) was not noted in either of the groups (Table 3) but psychomotor developmental index (PDI) score was significantly lower in the critical CHD group. In addition, there was a trend toward smaller brain volumes in the critical CHD patients compared with the VSD patients; this difference reached significance in frontal GM volume $(P<.05)$. Analysis of the relationship between total and regional brain volumes by 3D-MRI and neurodevelopmental score by Bayley II scale showed that frontal GM volume was weakly associated with PDI $(P<$ .01 ) but not MDI (Figure 4). No significant correlations were noted between any other regional brain volumes and neurodevelopmental score.

\section{DISCUSSION}

\section{Decreased Brain Volume and Fetal Circulation}

This is the first report of quantitative volumetric analysis of the brain in infants with CHD. A high incidence of microcephaly, presenting with reduced head circumference, has been reported in infants with complex CHD, especially those with HLHS. However, an imbalance of regional brain growth has not previously been reported. We identified decreased GM volume in infants with CHD, especially in those with critical and hypoxic CHD, even in the absence of visible injury on MRI. The etiology of this impaired neuroanatomic development in infants with CHD may be multifactorial, but most likely begins in utero. One potential cause is abnormal cerebrovascular blood flow dynamics in the fetus. Fetal cerebral vascular resistance has been shown to be abnormal in a variety of complex cardiac lesions. ${ }^{19,20}$ These alterations in cerebrovascular blood flow distribution may be associated with impaired brain growth. Fetuses with decreased cerebral oxygen supply display autoregulation of blood flow that enhances cerebral perfusion, a brain-sparing effect, which is most prominently found in fetuses with SV physiology, HLHS, and TGA. ${ }^{19}$ Inadequate cerebral blood flow in CHD fetuses, despite autoregulation by this brain-sparing effect, may alter brain growth. This theory may partly explain our finding that decreased brain volume occurs most prominently in infants with SV, HLHS, and TGA (critical CHD group).

\section{Preoperative Hypoxia and Brain Growth}

After birth, cerebral blood flow and oxygen delivery are low in infants with complex $\mathrm{CHD}^{21}$ and correlate with WM injury. Low diastolic blood pressure is seen in such patients, especially in infants receiving prostaglandin $\mathrm{E}_{1}$, as well as after systemic-pulmonary shunt operation, and 

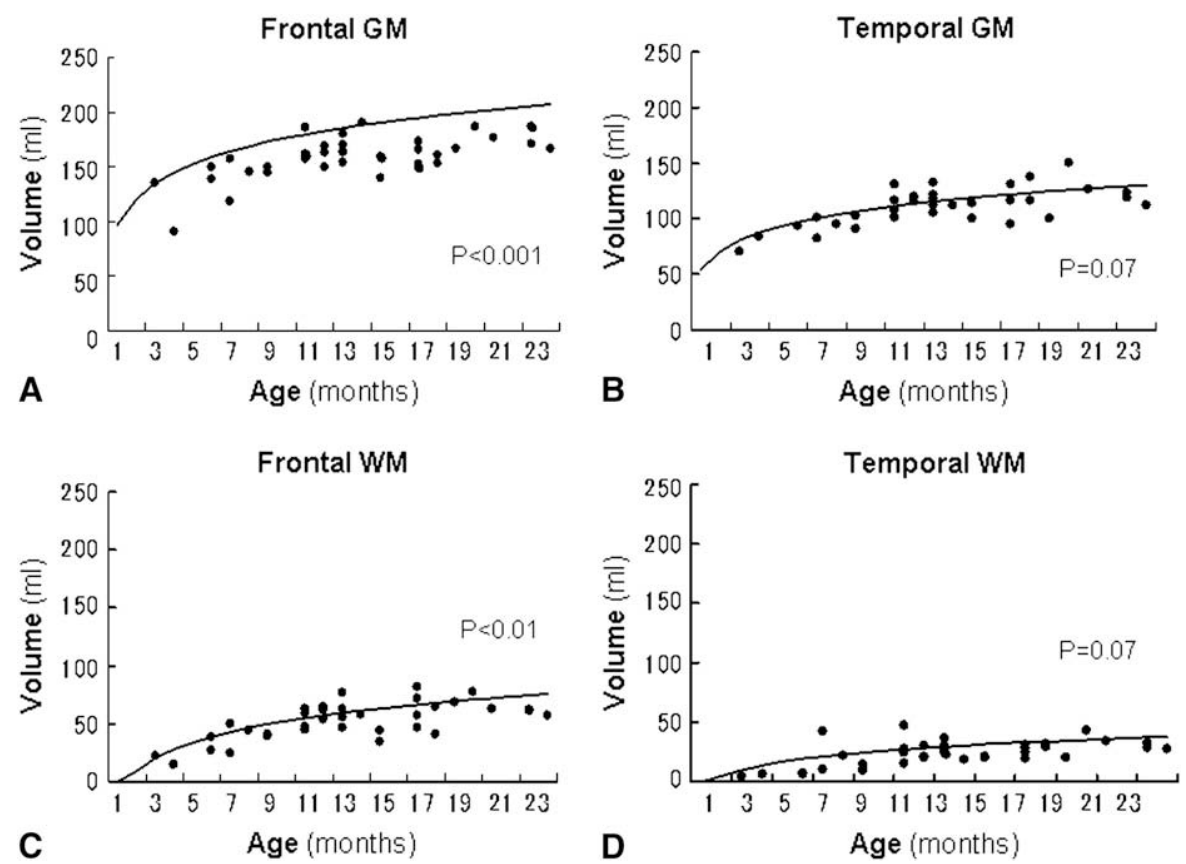

FIGURE 3. Regional brain volumes in patients with CHD compared with normal control values. The GM and WM volumes are significantly decreased in the frontal lobe (A and C) but not in the temporal lobes (B and D) in the patients with CHD. For GM and WM in the frontal lobe, the best fitting models for normal controls were as follows: $\mathrm{GM}=230.60+34.85 \times \mathrm{Z}$, where $\mathrm{Z}=\mathrm{In}(\mathrm{age} / 100)+0.76$; $\mathrm{WM},=93.48+26.68 \times \mathrm{Z}$, where $\mathrm{Z}=\mathrm{In}(\mathrm{age} / 100)+0.76$. For GM and $\mathrm{WM}$ in the temporal lobe, the best fitting models for normal controls were as follows: $\mathrm{GM}=146.14+23.94 \times \mathrm{Z}$, where $\mathrm{Z}=\mathrm{In}(\mathrm{age} / 100)+0.76$; $\mathrm{WM}=46.80$ $+13.37 \times \mathrm{Z}$, where $\mathrm{Z}=\mathrm{In}($ age $/ 100)+0.76$.

may predispose to WM injury as well as global cerebral ischemia. ${ }^{19}$ In our study, the majority of the infants in the critical CHD group were receiving prostaglandin $\mathrm{E}_{1}$ preoperatively, and the majority of the infants underwent systemic-pulmonary shunt operations. Low diastolic blood pressure coupled with hypoxia may partly affect brain growth in patients with critical CHD in our study. In addition to preoperative hypoxia and hypotension, perioperative

TABLE 2. Variables analyzed for association with reduced frontal gray matter volume

\begin{tabular}{lrcc}
\hline \multicolumn{1}{c}{ Variables (unit) } & $\begin{array}{c}\text { Regression } \\
\text { coefficient }\end{array}$ & $\mathbf{9 5 \%}$ CI & $\boldsymbol{P}$ value \\
\hline Patient-related variables & & & \\
Apgar score at 1 min & 0.0029 & $-0.0170<0.0224$ & NS \\
Birth head circumference (Z) & -0.0337 & $-0.0800<0.0128$ & NS \\
Age at latest operation (d) & -0.0000 & $-0.0002<0.0001$ & NS \\
Preop oxygen saturation (\%) & 0.0041 & $0.0012<0.0071$ & $<.01$ \\
Body weight at study (Z) & 0.0342 & $0.0021<0.0665$ & $<.05$ \\
Body height at study (Z) & -0.0196 & $-0.0450<0.0063$ & NS \\
Head circumference (Z) & 0.0290 & $-0.0190<0.0767$ & NS \\
Diagnosis-related variables & & & \\
$\quad$ Diagnosis of HLHS & -0.1351 & $-0.2680<-0.0020$ & $<.05$ \\
Perioperative variables & & & \\
$\quad$ ACC duration (min) & -0.0009 & $-0.0020<0.0004$ & NS \\
ECC duration (min) & 0.0005 & $-0.0005<0.0011$ & NS \\
$\quad$ Duration of intubation (d) & 0.0012 & $-0.0080<0.0105$ & NS \\
Duration of ICU stay (d) & 0.0037 & $-0.0060<0.0132$ & NS \\
\hline
\end{tabular}

For abbreviations see Table 1. $C I$, Confidence interval; $I C U$, intensive care unit.

factors including cardiac arrest, hyperglycemia or hypoglycemia, and hyperthermia may cause brain damage, but were not evident in our study, in agreement with previous reports. ${ }^{22,23}$

In addition, multivariate risk factor analysis showed the age at latest operation did not correlate with decreased GM volume (Table 2). However, the majority of the patients in the critical CHD group had neonatal surgery such as the

TABLE 3. Quantitative 3D-MRI of regional brain volume and neurodevelopmental score

\begin{tabular}{|c|c|c|c|}
\hline & VSD group $(\mathbf{n}=18)$ & $\begin{array}{c}\text { Critical CHD } \\
\text { group }(n=22)\end{array}$ & $P$ value \\
\hline \multicolumn{4}{|c|}{ Quantitative 3D-MRI of regional brain volume } \\
\hline Total GM & $0.948 \pm 0.056$ & $0.902 \pm 0.081$ & NS \\
\hline Total WM & $0.931 \pm 0.155$ & $0.848 \pm 0.188$ & NS \\
\hline CSF & $0.931 \pm 0.240$ & $0.840 \pm 0.180$ & NS \\
\hline Frontal GM & $0.895 \pm 0.060$ & $0.827 \pm 0.089$ & $<.05$ \\
\hline Frontal WM & $0.853 \pm 0.167$ & $0.766 \pm 0.184$ & NS \\
\hline Temporal GM & $1.005 \pm 0.094$ & $0.953 \pm 0.099$ & NS \\
\hline Temporal WM & $0.923 \pm 0.352$ & $0.824 \pm 0.318$ & NS \\
\hline \multicolumn{4}{|c|}{ Neurodevelopmental assessment by Bayley Scale } \\
\hline PDI & $96.5 \pm 15.3$ & $84.7 \pm 19.7$ & .05 \\
\hline MDI & $91.5 \pm 17.4$ & $97.6 \pm 19.8$ & NS \\
\hline
\end{tabular}



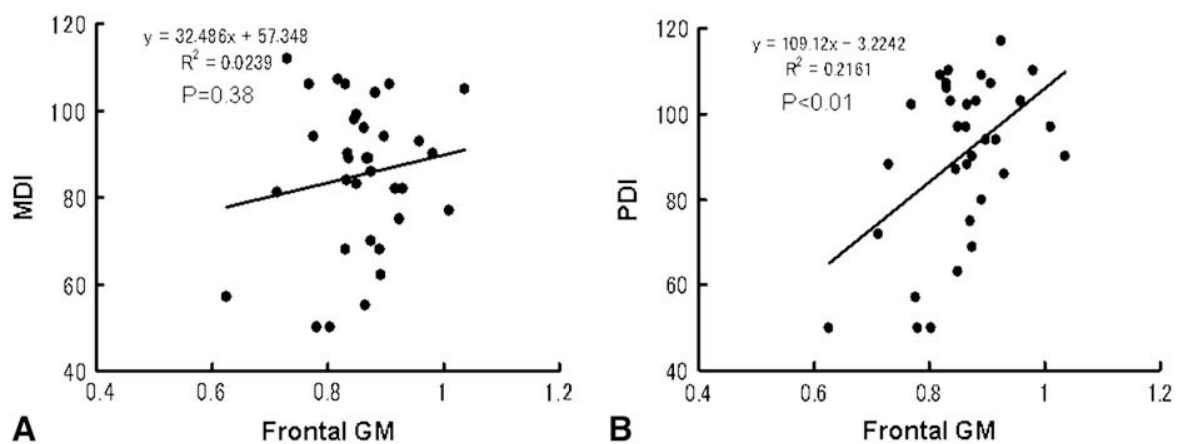

FIGURE 4. Correlation between neurodevelopmental score by Bayley II scale and frontal GM volume in patients with CHD. Frontal GM volume was weakly associated with PDI $(P<.01)(\mathrm{B})$ but not with MDI (A). Frontal GM volume is expressed as ratios to age-matched normal volumes. PDI, Psychomotor developmental index; $M D I$, mental developmental index.

Norwood operation, and this operation might influence the brain development greatly. Further, although we could not analyze this in the present study because of the small number of patients, the overall length of exposure to lower oxygen saturations might have had an impact on the findings of the MRI study, as well as the developmental testing.

\section{Decreased GM Volume in Infants with CHD}

A high incidence of WM injury, including periventricular leukomalacia occurs in neonates with CHD preoperatively and postoperatively ${ }^{24-27}$ and is thought to be related to hypoxia/ischemia to immature oligodendroglia in the process of myelination, which are most vulnerable to injury. ${ }^{27}$ On the contrary, little attention has been paid to GM injury and brain development in infants with CHD until now. This study documents for the first time a reduction in GM volume in infants with CHD, despite no significant reduction in WM volume. During the first 2 years after birth, brain volumes, especially GM, increase rapidly. ${ }^{28}$ This early growth spurt of the brain is the most prominent growth of any organs in the human body during this period. Further, the increase in GM is greater than in WM and reaches a maximum around 16 to 24 months of age, whereas the WM has a slower growth process throughout childhood. Therefore, if longlasting hypoxia/ischemia occurs in early infancy, GM would be more affected than WM and would result in a prominent reduction in the GM volume, as our study shows. Inder and associates $^{29}$ also reported that periventricular WM injury in the premature infant is followed by reduced cerebral cortical GM volume at term.

\section{Underdevelopment of Frontal GM and Delayed Psychomotor Development}

Of note, frontal GM volume, which includes the motor area, was positively but weakly associated with PDI score by Bayley II scale in our study. The correlation between the neuroanatomic changes and the neurodevelopmental function could be influenced by a number of factors, including the type of initial surgical intervention, the use of cardio- pulmonary bypass, and the perfusion techniques, as well as events related to hemodynamic instability and tendency to hypoxemia in the perioperative period. A neuropathologic study demonstrated that cerebral WM damage was the most significant lesion in 38 infants dying after cardiac surgery, followed by a spectrum of GM lesions, ${ }^{27}$ predominantly involving the cerebral cortex and hypocampus acutely, and the thalamus and brain stem (including the inferior oliva and basis pontis) more chronically. The common occurrence of injury in the inferior oliva and basis pontis suggests the possibility that dysfunction of cerebellar pathways contributes to the motor disturbances of survivors of cardiac surgery in early infancy. Similarly, underdevelopment of frontal GM, which includes the motor area, may be positively associated with psychomotor developmental delay in infants with critical CHD. Therefore, longer functional assessment should be undertaken, especially in infants with SV physiology, including HLHS, who have long-lasting hypoxia and staged reconstruction until ultimate conversion to Fontan circulation. Another association of structural underdevelopment of the brain, "open operculum," and developmental disabilities of feeding and language are also reported with high incidence in children with complex heart disease. ${ }^{21,24}$ Further research is needed to prove whether infants with developmental disabilities may have a structural underdevelopment of the brain as the etiology.

\section{Study Limitations}

In infants between 1 and 6 months of age, GM and unmyelinated WM have signal values that are isointense and are indistinguishable from one another. Therefore, when interpreting the results, we need to consider that GM in children under 6 months of age might include both GM and unmyelinated WM. However, in this study, only 2 infants under 6 months of age were enrolled, and they are unlikely to affect the conclusion.

The present study analyzed the volumes of the whole brain, fontal and temporal lobes, and did not analyze regional volumes of cortical subdivisions, such as premotor 
and sensorimotor regions. Quantitative information on regionally segmented brain volumes can be correlated with neurodevelopmental and behavioral measures to document the association between neuroanatomic development and the behavior repertoire and functional development. ${ }^{30}$

Our data were also limited by a lack of comparison with 3D-MRI data before surgery, because it was not possible to perform MRIs in most of the infants with critical CHD owing to their unstable general condition. Another limitation to this study is that longer functional assessments and follow-up 3D-MRI studies are not available. A relatively small patient population and variety of diagnostic categories also limit our study.

\section{CONCLUSION}

Brain developmental impairments occur in a number of infants with CHD, especially in those who have preoperative hypoxia and critical CHD. In addition, the impact of repeated procedures on patients undergoing staged palliation, as well as the age of initial intervention, could have an important role. A decrease in frontal GM volume, which includes the motor area, was weakly associated with psychomotor developmental delay in infants with critical CHD. This quantitative volumetric study encourages larger scale and longitudinal follow-up to elucidate the significance of impaired neuroanatomic development on functional outcome.

We acknowledge Professors Hikaru Seto, Takuro Misaki, Hisao Nishijo, Masayoshi Kurachi, Michio Suzuki, Makoto Nakazawa, and all members of the Japanese Study of Cognitive Function after Open Heart Surgery in Pediatric Patients for their pertinent suggestions and cooperation. We appreciate professors Makiko Osawa and Rumiko Matsuoka for their encouragement. We also thank Neil Bowles, Hiroki Michizu, and Yukimi Hirose for their excellent assistance.

\section{References}

1. Mahle WT, Spray TL, Wernovsky G, Gaynor JW. Clark BJ III. Survival after reconstructive surgery for hypoplastic left heart syndrome. Circulation. 2000;102: 136-41.

2. Weinstein S, Gaynor JW, Bridges ND, Wernovsky G, Montenegro LM, Godinez RI, et al. Early survival of infants weighting 2.5 kilograms or less undergoing first-stage reconstruction for hypoplastic left heart syndrome. Circulation. 1999; 100:167-70.

3. Tabbutt S, Nord AS, Jarvik GP, Bernbaum J, Wernovsky G, Gerdes M, et al. Neurodevelopmental outcomes after staged palliation for hypoplastic left heart syndrome. Pediatrics. 2008;121:476-83.

4. Wernovsky G. Current insights regarding neurological and developmental abnormalities in children and young adults with complex congenital cardia disease. Cardiol Young. 2006;16(Suppl 1):92-104.

5. Dittrich H, Buhrer C, Grimmer I, Dittrich S, Adbul-Khaliq H, Lange PE. Neurodevelopment at 1 year of age in infants with congenital heart disease. Heart. 2003; 89:436-41.

6. Limperopoulos C, Majnemer A, Shevell MI, Rosenblatt B, Rohlicek C, Tchervenkov C. Neurodevelopmental status of newborns and infants with congenital heart defects before and after open heart surgery. J Pediatr. 2000;137:638-45.

7. Wypij D, Jonas RA, Bellinger DC, del Nido PJ, Mayer JE, Bacha EA, et al. The effect of hematocrit during hypothermic cardiopulmonary bypass in infant heart surgery: results from the combined Boston hematocrit trials. J Thorac Cardiovasc Surg. 2008;135:355-60.
8. Karl TR, Hall S, Ford G, Kelly EA, Brizard CPR, Mee RBB, et al. Arterial switch with full-flow cardiopulmonary bypass and limited circulatory arrest: neurodevelopmental outcome. J Thorac Cardiovasc Surg. 2004;127:213-22.

9. Miller SP, McQuillen PS, Hamrick S, Xu D, Glidden DV, Charlton N, et al. Abnormal brain development in newborns with congenital heart disease. $N$ Engl J Med. 2007;357:1928-38.

10. Jonas RA, Wypij D, Roth SJ, Bellinger DC, Visconti KJ, du Plessis AJ, et al. The influence of hemodilution on outcome after hypothermic cardiopulmonary bypass: results of a randomized trial in infants. J Thorac Cardiovasc Surg. 2003; 126:1765-74.

11. Sarajuuri A, Jokinen E, Puosi R, Eronen M, Mildh L, Mattila I, et al. Neurodevelopmental and neuroradiologic outcomes in patients with univentricular heart aged 5 to 7 years: related risk factor analysis. J Thorac Cardiovasc Surg. 2007; 133:1524-32.

12. Markowitz SD, Ichord RN, Wernovsky G, Gaynor JW, Nicolson SC. Surrogate markers for neurological outcome in children after deep hypothermic circulatory arrest. Semin Cardiothorac Vasc Anesth. 2007;11:59-65.

13. Shillingford AJ, Ittenbach RF, Marino BS, Rychik J, Clancy RR, Spray TL, et al. Aortic morphometry and microcephaly in hypoplastic left heart syndrome. Cardiol Young. 2007; 17:189-95.

14. Matsuzawa J, Matsui M, Konishi T, Noguchi K, Gur RC, Bilker W, et al. Age-related volumetric changes of brain gray and white matter in healthy infants and children. Cereb Cortex. 2001;11:335-42.

15. Kohn MI, Tanna NK, Herman GT, Resnick SM, Mozley PD, Gur RE, et al. Analysis of brain and cerebrospinal fluid volumes with MR imaging. Radiology. 1991; 178:115-22.

16. Mozley PD, Gur RE, Resnick SM, Shtasel DL, Richards J, Kohn M, et al. Magnetic resonance imaging in schizophrenia: relationship with clinical measures. Schizophr Res. 1994;12:195-203.

17. Turetsky BI, Cowell PE, Gur RC, Grossman RI, Shtasel DL, Gur R. Frontal and temporal lobe brain volume in schizophrenia: relation to symptomatology and clinical subtype. Arch Gen Psychiatry. 1995;52:1061-70.

18. Royston P, Altman DG. Regression using fractional polynomials of continuous covariates: parsimonious parametric modelling (with discussin). Appl Statist. 1994;43:429-67.

19. Donofrio MT, Bremer YA, Schieken RM, Gennings C, Morton LD, Eidem BW, et al. Autoregulation of cerebral blood flow in fetuses with congenital heart disease: the brain sparing effect. Pediatr Cardiol. 2003;24:436-43.

20. Kaltman JR, Di H, Tian Z, Rychik J. Impact of congenital heart disease on cerebrovascular blood flow dynamics in the fetus. Ultrasound Obstet Gynecol. 2005; 25:32-6.

21. Licht DJ, Wang J, Silvestre DW, Nicolson SC, Montenegro LM, Wernovsky G, et al. Preoperative cerebral blood flow is diminished in neonates with severe congenital heart defects. J Thorac Cardiovasc Surg. 2004;128:841-9.

22. Gaynor JW, Wernovsky G, Jarvik GP, Bernbaum J, Gerdes M, Zackai E, et al Patient characteristics are important determinants of neurodevelopmental outcome at one year of age after neonatal and infant cardiac surgery. J Thorac Cardiovasc Surg. 2007; 133:1344-53.

23. Cottrell SM, Morris KP, Davies P, Bellinger DC, Jonas RA, Newburger JW. Early postoperative body temperature and developmental outcome after open heart surgery in infants. Ann Thorac Surg. 2004;77:66-71.

24. Mahle WT, Tavani F, Zimmerman RA, Nicolson SC, Galli KK, Gaynor JW, et al An MRI study of neurological injury before and after congenital heart surgery. Circulation. 2002;106:109-14.

25. Galli KK, Zimmerman RA, Jarvik GP, Wernovsky G, Kuypers MK, Clancy RR, et al. Periventricular leukomalacia is common after neonatal cardiac surgery. J Thorac Cardiovasc Surg. 2004;127:692-704.

26. Miller SP, McQuillen PS. Neurology of congenital heart disease: insight from brain imaging. Arch Dis Child Fetal Neonatal Ed. 2007;92:F435-7.

27. Kinney HC, Panigrahy A, Newburger JW, Jonas RA, Sleeper LA. Hypoxic-ischemic brain injury in infants with congenital heart disease dying after cardiac surgery. Acta Neuropathol. 2005;110:563-78.

28. Zhang LJ, Thomas KM, Davidson MC, Casey BJ, Heier LA, Ulug AM. MR quantitation of volume and diffusion changes in the developing brain. Am J Neuroradiol. 2005;26:45-9.

29. Inder TE, Huppi PS, Warfield S, Kikinis R, Zientara GP, Barnes PD, et al. Periventricular white matter injury in the premature infant is followed by reduced cerebral cortical gray matter volume at term. Ann Neurol. 1999;46:755-60.

30. Peterson BS, Vohr B, Staib LH, Cannistraci CJ, Dolberg A, Schneider KC, et al Regional brain volume abnormalities and long-term cognitive outcome in preterm infants. JAMA. 2000;284:1939-47. 